\title{
EFEITOS DA ATIVIDADE ANTIMICROBIANA DO EXTRATO BRUTO \\ ETANÓLICO DA PIPER SOLMSIANUM E EQUISETUM ARVENSE
}

Milton Sérgio Bohatch Júnior*, Luiz Antônio Esmerino,

Submetido em: 06/07/2015

Rosi Zanoni da Silva, Ana Márcia Volpato

Aceito em: 23/11/2015

Universidade Estadual de Ponta Grossa

Publicado em: 31/03/2016

*E-mail: milton.jr87@hotmail.com

\section{Resumo}

Com a finalidade de colaborar para a geração de fitoterápicos, o presente trabalho teve como objetivo realizar um screening da atividade antimicrobiana in vitro dos extratos das plantas Piper solmsianum e Equisetum arvense. Os rendimentos dos extratos brutos etanólicos foram de 18,6\% para folhas de $P$. solmsianum e de 6,7 \% para as partes aéreas de $E$. arvense. A atividade antimicrobiana foi testada frente ao Staphylococcus aureus ATCC 25923 e Escherichia coli ATCC 25922, utilizando o método de difusão em ágar cilindro em placas. Os extratos foram testados nas concentrações de $2000 \mu \mathrm{g}(1: 1), 1000 \mu \mathrm{g}(1: 2), 500 \mu \mathrm{g}$ (1:4), $250 \mu \mathrm{g}$ (1:8) e $125 \mu \mathrm{g}(1: 16)$ dissolvidos em DMSO. O extrato de $E$. arvense apresentou atividade antimicrobiana até a concentração de $125 \mu \mathrm{g}$ (1:16) para ambas as cepas testadas, com halo médio de inibição de 11,5 mm para S. aureus e 11 mm para E. coli. $O$ extrato bruto etanólico de $P$. solmsianum também apresentou atividade antimicrobiana até a concentração de $125 \mu \mathrm{g}(1: 16)$ para ambas as cepas, com halo médio de inibição de $15 \mathrm{~mm}$ para S. aureus e $11 \mathrm{~mm}$ para $E$. coli. A atividade antimicrobiana dos extratos testados foi considerada moderada tanto para microrganismos Gram positivo como Gram negativo.

Palavras-chave: Anti-infeccioso, Pplantas medicinais, Tteste de sensibilidade microbiana.

\section{Effects of antimicrobial activity of the crude ethanol extract of Piper solmsianum and Equisetum arvens}

\section{Abstract}

In order to contribute to the generation of herbal medicines, this study aimed to perform a screening in vitro of antimicrobial activity of Piper solmsianum and Equisetum arvense plants extracts. The yields of ethanol crude extracts went from $18.6 \%$ to leaves of $P$. solmsianum and $6.7 \%$ to the aerial parts of $E$. arvense. The antimicrobial activity was tested ahead with Staphylococcus aureus ATCC 25923 and Escherichia coli ATCC 25922, using the cylinder-plate method of diffusion on agar. The extracts were tested at concentrations of $2000 \mu \mathrm{g}(1: 1), 1000 \mu \mathrm{g}(1: 2), 500 \mu \mathrm{g}(1: 4), 250 \mu \mathrm{g}(1: 8)$ and 125 $\mu \mathrm{g}(1: 16)$ dissolved in DMSO. The extract of $E$. arvense showed antibacterial activity at the concentration of $125 \mu \mathrm{g}(1: 16)$ for both strains tested, with mean inhibition zone of $11.5 \mathrm{~mm}$ for $S$. aureus and $11 \mathrm{~mm}$ to $E$. coli. The crude ethanol extract of $P$. solmsianum also showed antibacterial activity at the concentration of $125 \mu \mathrm{g}(1: 16)$ for both strains tested, with mean inhibition zone of $15 \mathrm{~mm}$ for $S$. aureus and $11 \mathrm{~mm}$ to E. coli. The antimicrobial activity of the extracts was considered moderate for both Gram-negative as Gram-positive microorganisms.

Keywords: anti-infective agents, medicinal plants, microbial sensitivity tests. 


\section{Efectos de la actividad antimicrobiana del los extractos crudosbruto etanólico de PIPER SOLMSIANUM y EQUISETUM ARVENSE}

\section{Resumen}

Con el fin de contribuir para la generación de fitoterápicos, este estudio tuvo el objetivo de realizar un screening de la actividad antimicrobiana in vitro de los extractos de las plantas Piper solmsianum y Equisetum arvense. El rendimiento de los extractos brutos etanólicos fue $18,6 \%$ para las hojas de $P$. solmsianum y 6,7\% para las partes aéreas de $E$. arvense. La actividad antimicrobiana fue testada en oposición alStaphylococcus aureus ATCC 25923 y Escherichia coli ATCC 25922, utilizando el

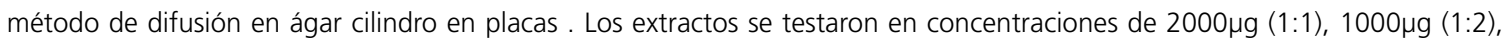
$500 \mu \mathrm{g}(1: 4), 250 \mu \mathrm{g}(1: 8)$ y $125 \mu \mathrm{g}(1: 16)$ disueltos en DMSO. El extracto $E$. arvense mostró actividad antimicrobiana, incluso

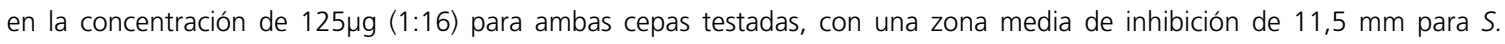
aureus y $11 \mathrm{~mm}$ para $E$. coli . El extracto crudo de etanol $P$. solmsianum también mostró actividad antimicrobiana incluso en la concentración de $125 \mu \mathrm{g}$ (1:16) para ambas cepas, con una zona media la inhibición de $15 \mathrm{~mm}$ para S. aureus y $11 \mathrm{~mm}$ para E. coli . La actividad antimicrobiana de los extractos testados fue considerada moderada para ambos microorganismos, Gram positivo y Gram negativo.

Palabras-clave: aAnti-infecciosos. pPlantas medicinales. pPruebas de sensibilidad microbiana.

\section{INTRODUÇÃO}

A indústria farmacêutica caracteriza-se pela alta tecnologia e rápido crescimento. Grande parte dos medicamentos industrializados que hoje estão no mercado, originou-se de produtos naturais. O potencial antimicrobiano proveniente de plantas medicinais é de grande interesse na área farmacêutica devido às inúmeras doenças de origem microbiana e a resistência que os microrganismos adquirem frente aos medicamentos de uso tradicional(1).

Apesar da disponibilização de novos antibióticos, a resistência bacteriana ocorre em ritmo crescente nos diferentes patógenos Gram positivos e Gram negativos e representa um grande desafio terapêutico(2), levando a uma necessidade premente de novas classes de substâncias antibacterianas, especialmente a partir de fontes naturais.

Os extratos vegetais são uma alternativa terapêutica para o tratamento de microrganismos multirresistentes, apresentando muitas vantagens: menor efeito colateral, melhor tolerância do paciente, mais econômico, melhor aceitação devido à longa história de uso na medicina popular e ser renovável por estar disponível na natureza $(3,4)$.

A combinação de produtos naturais com antibióticos disponíveis na prática clínica mostra-se como uma alternativa importante e economicamente mais viável, uma vez que o efeito sinérgico entre ambos pode proporcionar uma maior atividade antibacteriana frente a microrganismos sensíveis e resistentes. Dessa forma, o efeito potencializado dessas associações pode servir como nova estratégia para tratamento de infecções em pacientes críticos e no combate a cepas multirresistentes(5).

O Staphylococcus aureus, uma bactéria Gram positiva, é um importante agente etiológico de infecções humanas, sendo encontrado como microbiota normal nas fossas nasais, virilha e axilas. É responsável por diferentes tipos de infecções; na maioria dos casos, as infecções são leves acometendo pele e tecidos moles, mas podem apresentar-se sob formas graves de pneumonia, endocardites e sepse, com elevadas morbidade e mortalidade(6). O Staphylococcus aureus meticilina resistente (MRSA) está entre os patógenos mais envolvidos em infecções hospitalares, sendo responsável por inativar a ação de vários antibióticos(7). No Brasil, os índices de cepas MRSA são altos (40\% a $80 \%)$, principalmente em UTIs(8).

A Escherichia coli é uma bactéria Gram negativa, de distribuição ubíqua, na qual a grande maioria das cepas pertence à microbiota intestinal; cerca de $10 \%$ são patogênicas, podendo causar infecções intestinais e extraintestinais $(9,10)$. É o 
microrganismo mais frequentemente isolado no meio hospitalar, sendo também o mais proeminente agente etiológico das infecções urinárias, septicemias e meningites bacterianas nos neonatos(11).

Tendo em vista que bactérias resistentes a múltiplos antimicrobianos representam um desafio no tratamento de infecções, é notória a necessidade de se encontrar novas substâncias com propriedades antimicrobianas para serem utilizadas no controle desses microrganismos. A seleção de plantas a partir de informações da medicina tradicional ou popular pode conduzir a descoberta de moléculas promissoras(12). Entre as espécies vegetais reconhecidas pelo seu potencial antisséptico na medicina popular, destacam-se a Piper solmsianum var. solmsianum, conhecida popularmente por pariparoba, e Equisetum arvense, conhecida popularmente como cavalinha ou "rabo de cavalo"(13).

A Equisetum arvense é amplamente encontrada nas Américas, Europa e no norte da África e da Ásia, sendo empregada tradicionalmente como diurética, anti-inflamatória e remineralizante(14). A Piper solsianum, da família Piperaceae, é distribuída em regiões de clima tropical, sendo a maior diversidade dessa planta encontrada no continente americano seguido da Ásia. Espécies de Piper têm sido utilizadas na medicina popular como agentes antitumorais e antissépticas(15).

Com a finalidade de colaborar para a geração de fitoterápicos com atividade antibacteriana, o presente trabalho teve como objetivo realizar um screening da atividade antimicrobiana in vitro dos extratos das plantas Piper solmsianum e Equisetum arvense frente a microrganismos de grande prevalência em nosso meio, Staphylococcus aureus e Escherichia coli.

\section{MATERIAIS E MÉTODOS}

\section{Coleta das Plantas}

As folhas de Piper solmsianum var. solmsianum foram coletadas na Universidade Estadual de Ponta Grossa, Bloco M, durante o mês de março. As partes aéreas de Equisetum arvense foram coletadas na Vila Estrela/ Ponta Grossa durante o mês de março e ambas foram secadas a temperatura ambiente por sete dias. Posteriormente, foram moídas em moinho de facas com tela de $3 \mathrm{~mm} \mathrm{IKL}$.

\section{Obtenção dos extratos brutos etanólicos}

As folhas secas de Piper solmsianum $(9,4 \mathrm{~g})$ e as partes aéreas secas de Equisetum arvense (10,0g), estabilizadas e moídas, foram submetidas a extração com etanol $96^{\circ} \mathrm{GL}$ em Soxhlet até esgotamento. O tempo de refluxo foi de 18 horas para ambos os vegetais. O material obtido foi concentrado em evaporador rotatório a vácuo e sob temperatura controlada de 40 a $450 C$ até completa evaporação do solvente, obtendo-se assim os extratos brutos etanólicos das folhas de $P$. solmsianum e das partes aéreas de $E$. arvense.

\section{Microrganismos}

Para a determinação da atividade antimicrobiana foram utilizadas cepas padrão provenientes da American Type Culture Collection (ATCC): Staphylococcus aureus ATCC 25923 e Escherichia coli ATCC 25922.

\section{Preparação dos inóculos}

No preparo do inóculo, inicialmente foi feita uma suspensão bacteriana, utilizando uma cultura recente (24 horas). A concentração foi padronizada comparando a turbidez do inóculo com o padrão 0,5 da escala de MacFarland em espectrofotômetro 
$(580 \mathrm{~nm})$. Essa turvação é semelhante à padronizada para o antibiograma e o resultado da absorbância deve estar entre 0,08 e 0,10 , o que equivale a 1,5 ×108 UFC/mL(16,17). Cada suspensão de microrganismo foi semeada (em duplicata), com auxílio de um swab, em toda a superfície de meio Agar Muller-Hinton em placas de petri $(150 \mathrm{~mm})$ contendo $40 \mathrm{~mL}$ do meio de cultura Agar Miller-Hinton, para obtenção de um inóculo uniforme.

\section{Teste de atividade antimicrobiana}

Para avaliação da atividade antimicrobiana dos extratos, foi empregado o método de difusão em Ágar cilindro em placas $(16,18)$ e diferentes concentrações dos extratos estudados foram utilizados, com o objetivo de se determinar a Concentração Inibitória Mínima (CIM) em relação ao diâmetro dos halos de inibição.

Após a inoculação das placas com a suspensão bacteriana padronizada foram colocados, sobre a superfície do meio, os cilindros de aço inoxidável (10 mm de altura; diâmetros interno e externo de 6 e $8 \mathrm{~mm}$, respectivamente), a uma distância de $30 \mathrm{~mm}$ um do outro. Os cilindros foram previamente lavados, colocados em uma solução de ácido nítrico $2 \mathrm{~N}$ e esterilizados em autoclave $120^{\circ} \mathrm{C}$ por 15 minutos.

Em seguida, os cilindros foram preenchidos com $100 \mu \mathrm{L}$ dos extratos bruto etanólico, nas concentrações decrescentes, partindo-se de 2000 $\mu \mathrm{g}$ (1:1), $1000 \mu \mathrm{g}$ (1:2), $500 \mu \mathrm{g}$ (1:4), $250 \mu \mathrm{g}$ (1:8) e $125 \mu \mathrm{g}$ (1:16), dissolvidos em dimetilsulfóxido (DMSO). 0 teste foi realizado em duplicata. Como controle negativo, utilizou-se o DMSO; e como controle positivo utilizou-se cloranfenicol $(30 \mu \mathrm{g})$, com uma distância de aproximadamente um centímetro da parede da placa, com cuidado para não danificar o meio de cultura. As placas foram incubadas a $35^{\circ} \mathrm{C}$ em estufa bacteriológica por $24 \mathrm{~h}$. Posteriormente, foi realizada a leitura dos halos de inibição formados ao redor dos cilindros contendo os extratos. A leitura dos resultados foi realizada medindo-se o diâmetro dos halos, em mm, formados ao redor dos cilindros contendo os extratos.

\section{RESULTADOS}

A extração contínua por Soxhlet a quente nos permitiu obter um rendimento dos extratos brutos etanólicos: de 18,6\% para folhas de $P$. solmsianum e de $6,7 \%$ para as partes aéreas de $E$. arvense.

Com relação à atividade antimicrobiana do extrato de $E$. arvense observou-se atividade antimicrobiana até a concentração de $125 \mu \mathrm{g}$ (1:16) para ambas as cepas testadas, com halo médio de inibição de 11,5 mm para S. aureus e $11 \mathrm{~mm}$ para E. coli (TABELA 1).

TABELA 1: Resultado da leitura dos halos de inibição obtidos pela média aritmética de concentrações decrescentes de Equisetum arvense pela técnica cilindro em placas.

\begin{tabular}{|lccccccc|}
\hline & \multicolumn{3}{c}{ Concentração do extrato bruto de Equisetum arvensis ( $\boldsymbol{\mu g})$} & \multicolumn{2}{c|}{ Controles } \\
\hline Microrganismo & $\mathbf{2 0 0 0}$ & $\mathbf{1 0 0 0}$ & $\mathbf{5 0 0}$ & $\mathbf{2 5 0}$ & $\mathbf{1 2 5}$ & $\mathbf{1}$ & $\mathbf{2}$ \\
\hline $\begin{array}{l}\text { Staphylococcus aureus ATCC } \mathbf{2 5 9 2 3} \\
\text { Halo de inibição (mm) }\end{array}$ & 13,5 & 12,5 & 12 & 12 & 11,5 & $\mathrm{R}$ & 6 \\
\hline $\begin{array}{l}\text { Escherichia coli ATCC 25923 } \\
\text { Halo de inibição (mm) }\end{array}$ & 11,5 & 11,5 & 11 & 11 & 11 & $\mathrm{R}$ & 9 \\
\hline
\end{tabular}

R: resistente; C1: controle negativo - DMSO; C2: controle positivo - cloranfenicol. 
No extrato bruto etanólico de $P$. solmsianum, pode-se observar também uma atividade antimicrobiana até a concentração de $125 \mu \mathrm{g}$ (1:16) para ambas as cepas testadas, com halo médio de inibição de $15 \mathrm{~mm}$ para S. aureus e $11 \mathrm{~mm}$ para E. coli (TABELA 2).

TABELA 2: Resultado da leitura dos halos de inibição obtidos pela média aritmética de concentrações decrescentes de Piper solmsianum pela técnica cilindro em placas.

\begin{tabular}{|c|c|c|c|c|c|c|c|}
\hline \multirow{2}{*}{ Microrganismo } & \multicolumn{5}{|c|}{ Concentração do extrato bruto de Piper solmsianum $(\mu \mathrm{g})$} & \multicolumn{2}{|c|}{ Controles } \\
\hline & 2000 & 1000 & 500 & 250 & 125 & 1 & 2 \\
\hline $\begin{array}{l}\text { Staphylococcus aureus ATCC } 25923 \\
\text { Halo de inibição (mm) }\end{array}$ & 17,5 & 16 & 16 & 16 & 15 & $\mathrm{R}$ & 8 \\
\hline $\begin{array}{l}\text { Escherichia coli ATCC } 25923 \\
\text { Halo de inibição (mm) }\end{array}$ & 14,5 & 14,5 & 12 & 12,5 & 11 & $\mathrm{R}$ & 9 \\
\hline
\end{tabular}

R: resistente; C1: controle negativo - DMSO; C2: controle positivo - cloranfenicol.

\section{DISCUSSÕES}

As propriedades antimicrobianas têm sido comprovadas através de intensivas pesquisas em todo o mundo. Um screening inicial do potencial antibacteriano para compostos fitoquímicos pode ser realizado para extratos brutos ou semi-purificados(19). Os ensaios de atividade antimicrobiana se referem a diferentes técnicas ou métodos laboratoriais in vitro utilizados para determinar o potencial antimicrobiano de um determinado agente. Estes ensaios são realizados por meio de técnicas padronizadas, como os métodos de difusão em meio sólido e o método cilindro em placa utilizado neste experimento(18,20).

Diferentemente do que ocorre com os agentes antibióticos e quimioterápicos, há poucos registros na literatura quanto ao possível mecanismo de ação de produtos oriundos de plantas. Os compostos isolados de plantas são substâncias com estruturas químicas bem diferenciadas dos antimicrobianos obtidos a partir de microrganismos. Tais produtos podem atuar no metabolismo intermediário, ativando enzimas, alterando a ação de inibidores que influenciam os nutrientes do meio, interferindo nos processos enzimáticos em nível nuclear ou ribossômico, provocando alterações nas membranas ou ainda interferindo no metabolismo secundário(21).

Resultados semelhantes para os extratos brutos de Equisetum arvense $(21,22,23)$ e Piper solmsianum(24,25) foram reportados em outros estudos. Sinha(22), utilizando método de difusão em ágar, demonstrou atividade antibacteriana da $E$. arvense contra microrganismos Gram-positivos e Gram-negativos, sendo esta atividade presumida pela presença de compostos fenólicos, taninos, terpenóides, alcalóides e flavonóides no extrato etanólico dessa planta. Naturforsch et al.(24), utilizando ensaios de bioautografia, demonstraram a atividade antimicrobiana do extrato metanólico de Piper solmsianum, particularmente contra as bactérias Gram-positivas (Bacillus cereus, Staphylococcus aureus, Staphylococcus saprophyticus e Streptococcus agalactiae). Os autores sugeriram que a atividade antimicrobiana possa estar relacionada à presença de conocarpanos e Eupomatenóide-5 (neolignanas).

As variações referentes à determinação da CIM de extratos de plantas podem ser atribuídas a vários fatores. Dentre eles, podemos citar a técnica aplicada, o microrganismo e a cepa utilizada no teste, à origem da planta, a época da coleta, se os 
extratos foram preparados a partir de plantas frescas ou secas e a quantidade de extrato testada. Assim, não existe método padronizado para expressar os resultados de testes antimicrobianos de produtos naturais(26).

Um estudo propôs uma classificação para materiais vegetais com base nos resultados da CIM, considerando como forte

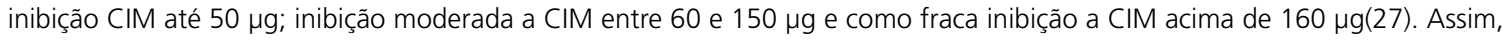
os extratos de ambas as plantas apresentaram atividade antimicrobiana até a diluição 1:16 o que corresponde a 125 $\mu$ g. De acordo com a classificação supracitada, os extratos apresentam atividade antimicrobiana moderada tanto para bactérias Gram positiva como Gram negativa. Identificada a atividade nos extratos, estudos complementares são necessários para isolar as substâncias com potencial terapêutico, podendo, inclusive, contribuir para a descoberta compostos que possam ser utilizados como protótipos moleculares para geração de novos fármacos.

\section{CONCLUSÕES}

Com base nas condições do experimento, as plantas medicinais Piper solmsianum e Equisetum arvense apresentaram atividade antimicrobiana frente aos microrganismos Staphylococcus aureus ATCC 25923 e Escherichia coli ATCC 25923. Na maior diluição 1:16 (125 $\mu \mathrm{g})$, ambas as plantas apresentaram atividade antimicrobiana moderada. EsSe estudo corrobora com a importância de levantamentos etnofarmacológicos na seleção de plantas medicinais para triagem de bioatividade. Os resultados apresentam uma expressiva contribuição para a caracterização da atividade antimicrobiana dos extratos brutos etanólicos da flora brasileira utilizados na medicina tradicional.

\section{REFERÊNCIAS}

1. Guimarães DO, Momesso LS, Pupo MT. Antibióticos: importância terapêutica e perspectivas para a descoberta e desenvolvimento de novos agentes. Quim. Nova, 2010; 33(3): 667-679.

2. Rossi F, Andreazzi D. Resistência bacteriana: Interpretando o antibiograma. São Paulo: Ed. Atheneu; 2005. p.118.

3. Gur S, Turgut-Balik D, Gur N. Antimicrobial activities and some fatty acids of turmeric, ginger root and linseed used in the treatment of infectious diseases. World Journal of Agricultural Sciences. 2006; 2(4):439-42.

4. Parekh J, Chanda SV. In vitro antimicrobial activity and phytochemical analysis of some Indian medicinal plants. Turkish Journal of Biology. 2007; 31: 53-58.

5. Kumar AS, Venkateshwaran K, Vanitha J, Saravanan VS, Ganesh M, Vasudevan M, Sivakumar T. Synergistic activity of methanolic extract of Thespesia populnea (Malvaceae) flowers with oxytetracycline. Bangladesh J Pharmacol. 2009; 4(1): 13-16.

6. Menegotto FR, Picoli SU. Staphylococcus aureus oxacilina resistente (MRSA): incidência de cepas adquiridas na comunidade (CA-MRSA) e importância da pesquisa e descolonização em hospital. Revista Brasileira de Análises Clínicas. 2007; 39(2): 147-150.

7. Stratton CW. Nuances in antimicrobial susceptibility testing for resistant gram-positive organisms. Antimicrobics and Infectious Diseases Newsletter. 2000; 18(8): 57-64.

8. ANVISA - Agência Nacional de Vigilância Sanitária. Projeto Hospitais sentinela: Brasília: Ministério da Saúde (BR) [cited 2015 may 22]. Disponível em: http://www.anvisa.gov.br/servicosaude/hsentinela/index.htm. 
9. Kaper JB, Nataro J, Mobley HLT. Pathogenic Escherichia coli. Nature Reviews Microbiology. 2004; 2: 123-140.

10. Johnson JR, Russo TA. Molecular epidemiology of extraintestinal pathogenic (uropathogenic) Escherichia coli. International Jounal of Medical Microbiology. 2005; 295 (6-7): 383-404.

11. Kahlmeter $G$. An international survey of the antimicrobial susceptibility of pathogens from uncomplicated urinary tract infections: the ECO.SENS Project. Journal of Antimicrobial Chemotherapy. 2003; 51(1): 69-76.

12. Santos SC, Ferreira FS, Rossi-Alva JC, Fernandez LG. Atividade antimicrobiana in vitro do extrato de Abarema cochliocarpos (Gomes) Rev. bras. Farmacogn. 2007; 17(2): 215-219.

13. Pessini GL, Dias Filho BP, Nakamura CV, Cortez DAG. Antifungal Activity of the Extracts and Neolignans from Piper regnellii (Miq.) C. DC. var. pallescens (C. DC.) Yunck. Journal of the Brazilian Chemical Society. 2005; 16(6a): 1130-1133.

14. Mimica-Dukic N, Simin N, Cvejic J, Jovin E, et al. Phenolic compounds in field horsetail (Equisetum arvense L.) as natural antioxidants. Molecules. 2008; 13(7): 1455-1464.

15. Jaramillo MA and Manos PS. Phylogeny and patterns of floral diversity in the genus Piper (Piperaceae). American Journal of Botany. 2001; 88: 706-716.

16. United States Pharmacopeial Convention. The United States pharmacopeia: the national formulary. São Paulo: Ed. Easton; 1990. 2067 p.

17. NCCLS (NATIONAL COMMTTEE FOR CLINICAL LABORATORY STANDARDS). Performance Standards for Antimicrobial Susceptibility Testting. Wayne: NCCLS; 2002. 133 p.

18. Esmerino LA, Pereira AV, Admowicz T, Borges DM, Talacimon EA, Schelesky MH. Método microbiológico para determinação da potência de antimicrobianos. Publicatio UEPG Ciências Biológicas e da Saúde. 2004; 10(1): 53-60.

19. Silva O, Duarte A, Cabrita J, Pimentel M, Diniz A, Gomes E. Antimicrobial activity of Guinea-Bissau traditional remedies. J. Ethnopharmacol. 1996; 50(1): 55-59.

20. Campos MB, Costa ALP, Barbosa LPJL, Barbosa HPB. Análise qualitativa fitoquímica e atividade antimicrobiana do extrato bruto hidroalcoólico da casca de Bertholletia excelsa Humb. \& Bomple (Lecytidaceae) frente a microrganismos gramnegativos. Ciência Equatorial. 2011; 1(2): 6-14.

21. Cowan MM. Plant products as antimicrobial agents. Clin. Microbiol. Rev. 1999; 12(4): 564-82.

22. Sinha SN. In vitro Antibacterial Activity of Ethanolic Extract of Equisetum arvense L. IJPBR. 2012; 3 (1): 19-21.

23. Dahanukar SA, Kulkarni RA, Rege NN. Pharmacology of Medicinal Plants and Natural products. Indian J Pharmacology. 2000; 32: 118.

24. Campos MP, Cechinel Filho V, Silva RZ, Yunes RA, Monache FD, Cruz AB. Antibacterial activity of extract, fractions and four compounds extracted from Piper solmsianum C. DC. var. solmsianum (Piperaceae). Z Naturforsch. 2007;62(3-4):173-178.

25. Lopes MA, Ferracioli KR, Siqueira VL, de Lima Scodro RB, Cortez DA, da Silva RZ et al. In vitro interaction of eupomatenoid-5 from Piper solmsianum C. DC. var. solmsianum and anti-tuberculosis drugs. Int J Tuberc Lung Dis. 2014; 18(12): 1513-1515.

26. Fennel CW, Lindsey KL, Mc Gaw LJ, Sparg SG, Stafford GI, Elgorashi EE et al. Review: Assessing African medicinal plants for effi cacy and safety: Pharmacological screening and toxicology. J. Ethnopharmacol. 2004; 94: 205-217.

27. Aligiannis N, Kalpoutzakis E, Mitaku S, Chinou IB. J. Agric. Food Chem. 2001; 49(9): 4168-70. 